\title{
Effect of Chronic Digoxin on $\beta$-Adrenergic Receptors in Rabbits with Heart Failure
}

\author{
Wurin AlbajinaI, MD, Tsutomu Yoshikawa, MD, \\ Masahiro Suzuki, MD, Keiichi NagAMI, MD, \\ Yumiko WaINAI, MD, \\ and Shunnosuke HANDA, ${ }^{1}$ MD
}

\begin{abstract}
SUMMARY
This study investigated the effect of chronic digitalis glycoside use on $\beta$ adrenergic sympathetic activities in heart failure. Twenty-two Japanese white rabbits were anesthetized by intravenous injection of chloral hydrate. Aortic regurgitation (AR) was produccd by perforating aortic valves in 14 rabbits. Digoxin was given for 1 week to 7 rabbits with $A R(A R+D i g)$ and saline to 7 rabbits with $A R(A R+C)$. Sham operation was performed in the remaining 8 rabbits $(\mathrm{S})$. The left ventricular end-diastolic pressure was higher in $\mathrm{AR}+\mathrm{C}$ than $\mathrm{S}(p<0.05)$. It was lower in $\mathrm{AR}+\mathrm{Dig}$ than $\mathrm{AR}+\mathrm{C}(p<0.05)$. Cardiac output was lower in $\mathrm{AR}+\mathrm{C}$ than $\mathrm{S}(p<0.05)$. There was no difference between $\mathrm{AR}+$ Dig and S. Both the left ventricular end-diastolic and end-systolic diameters were larger in $\mathrm{AR}+\mathrm{C}(p<0.05)$ than $\mathrm{S}$, but they were similar between $\mathrm{AR}+\mathrm{Dig}$ and $\mathrm{S}$. Plasma norepinephrine level was lower in $\mathrm{AR}+$ Dig than $\mathrm{AR}+\mathrm{C}$. Myocardial $\beta$-adrenergic receptors number determined by radioligand binding assay using $30-800 \mathrm{pM}{ }^{125}$ I-iodocyanopindolol was lower in $\mathrm{AR}+\mathrm{C}$ than $\mathrm{S}(28.8 \pm 7.9$ vs. $69.9 \pm 12.3 \mathrm{fmol} / \mathrm{mg}$ protein, $p<0.05)$. It was higher in $\mathrm{AR}+\mathrm{Dig}(39.9 \pm 9.8)$ than $\mathrm{AR}+\mathrm{C}(p<0.05)$. Myocardial norepinephrine content was lower in both $\mathrm{AR}+\mathrm{C}(p<0.05)$ and $\mathrm{AR}+$ Dig than $\mathrm{S}$ $(p<0.05)$. Thus, digitalis glycosides exert favorable effects on $\beta$-adrenergic sympathetic activitics in addition to the effects on hemodynamic variables in this animal model of heart failure. (Jpn Heart $\mathrm{J}$ 1997; 38: 263-272)
\end{abstract}

Key words: Digitalis glycosides, Heart failure, $\beta$-adrenergic receptor, Aortic regurgitation, Rabbits

7 HERE is still controversy regarding the optimal therapeutic strategy for long-term management of patients with congestive heart failure. Catecholamines or phosphodiesterase inhibitors possess a potent inotropic efficacy, but long-term use results in an attenuation of its efficacy and may even adversely

From Cardiopulmonary Division, Department of Medicine, Keio University School of Medicine, Tokyo, and 'First Department of Internal Medicine, Tokai University School of Medicine, Sagamihara, Japan.

Address for correspondence: Tsutomu Yoshikawa, MD, Cardiopulmonary Division, Department of Medicine, Keio University School of Medicine, 35 Shinanomachi, Shinjuku-ku, Tokyo 160, Japan.

Received for publication July 15, 1996.

Accepted September 30, 1996. 
affect survival in patients with heart failure. ${ }^{1-3)}$ Digitalis glycosides have been used as a baseline drug for heart failure for more than 200 years. The inotropic response to digoxin is maintained in papillary muscle preparations derived from patients with endstage heart failure who underwent cardiac transplantation ${ }^{4)}$ which is quite different to that of catecholamines and phosphodiesterase inhibitors. Recent reports have shown that long-term use of the drug had some favorable effects despite the modest inotropic potency, ${ }^{5,6)}$ although the effect on overall survival was found to be neutral.

Myocardial $\beta$-adrenergic receptors are down-regulated in ventricular myocardium from patients with severe congestive heart failure. ${ }^{7)}$ Clinical observations show that digitalis glycosides attenuate excessive activation of the sympathetic nervous system ${ }^{8}$ through sensitization of the carotid sinus baroreflex of parasympathetic activity which is profoundly disturbed in congestive heart failure. ${ }^{9)} \mathrm{A}$ recent report has shown that ouabain binding sites are reduced in failing myocardium, and this change was prevented by $\beta$-blocker. ${ }^{10)}$ In addition, a reduction in ouabain binding sites is produced by long-term use of norepinephrine. ${ }^{11)}$ It is hypothesized that ouabain-binding sites have some interactions with sympathetic nerve traffic. The present study was designed to examine the effects of chronic digitalis glycoside use on cardiac performance and $\beta$-adrenergic receptors in heart failure produced by aortic regurgitation in rabbits.

\section{Methods and Materials}

All animal experiments were performed in accordance with the "Guidelines for the Care and Use of Laboratory Animals" published by the US National Institutes of Health, and were approved by the Institutional Committee on Animal Experiment Ethics of Keio University School of Medicine.

Production of aortic regurgitation: Twenty-two Japanese white rabbits were anesthetized by intravenous administration of chloral hydrate $(150 \mathrm{mg} / \mathrm{kg})$. Aortic regurgitation was produced in 14 rabbits as described previously. ${ }^{12,13)}$ The right carotid artery was isolated from surrounding tissue. Aortic pressure was measured with a $5 \mathrm{~F}$ micromanometer-tipped catheter. A $5 \mathrm{~F}$ metal catheter was introduced from the right carotid artery and advanced toward the aortic root. The catheter was pushed toward the left ventricle where aortic valve motion was optimally detectable. Diastolic murmur was audible after the successful creation of aortic regurgitation which was confirmed by measuring the reduction in aortic diastolic pressure that was found to predict subsequent left ventricular overloading in our previous studies. ${ }^{12,13)}$ Sham operation was performed in another 8 rabbits in which aortic pressure was measured but aortic regurgitation not produced. After the procedure, the carotid artery was ligated, the wound sutured 
and antibiotics injected.

Administration of digitalis glycosides: $0.25 \mathrm{mg} / \mathrm{kg}$ of digoxin was injected intravenously in 8 rabbits with aortic regurgitation (AR + Dig). Thereafter, digoxin was injected continuously at the rate of $2.0 \mu \mathrm{g} / \mathrm{kg} / \mathrm{hr}$ using an osmotic minipump (Alzet 2ML1, Alza Corp., Palo Alto, CA, USA) implanted subcutaneously for one week. Physiological saline was injected as a control in the same manner in the other 7 rabbits with aortic regurgitation $(A R+C)$.

Measurement of hemodynamic data: Hemodynamic data were collected under an open-chest anesthetized condition one week after the procedure. Ventilation was controlled via the intubation tube $(4.0$ or $4.5 \mathrm{~mm}$ in internal diameter), introduced from the tracheal incision. Tidal volume was adjusted to $50 \mathrm{~m} l$ and frequency was $20 / \mathrm{min}$. Aortic root pressure was measured by a $5 \mathrm{~F}$ micromanometer-tipped catheter (PC-350, Millar Instruments, Houston, TX, USA), introduced from the left carotid artery. The left ventricular pressure was measured by a $3 \mathrm{~F}$ micromanometer catheter (PC-330, Millar Instruments), introduced from an apical incision. The left ventricular diameter was measured by a pair of piezoelectric crystals attached to the anterior and posterior epicardial surface. Aortic flow was measured by an electromagnetic flow probe (MFV120, Nihon-Kohden, Tokyo) placed around the aortic root. After the collection of hemodynamic data, heart beat was stopped by rapid injection of potassium chloride, and coronary arteries were flushed with ice-cold physiological saline to completely eliminate residual blood. The left ventricular free wall was isolated, weighed and its thickness determined.

Membrane preparation: Approximately $0.5 \mathrm{~g}$ of the left ventricular myocardium was rapidly frozen by liquid nitrogen for determination of catecholamine content. ${ }^{14)}$ The remaining myocardium was processed for membrane preparation for $\beta$-adrenergic receptor assay as described previously. ${ }^{15,16)}$ The left ventricular myocardium was soaked in ice-cold isotonic sucrose buffer $(250 \mathrm{mM}$ sucrose, 1 $\mathrm{mM} \mathrm{KHCO}_{3}, 1 \mathrm{mM} \mathrm{MgCl}{ }_{2}$ ). Connective tissues, pericardium and endocardium were removed as much as possible and minced with scissors. They were homogenized with a tissue disrupter (Physcotron, Niti-on, Chiba, Japan) at maximal speed for 5 seconds and filtered through two layers of Japanese silk screen. The homogenates were centrifuged at $700 \mathrm{~g}$ for 10 minutes to remove nuclei and remaining connective tissues. The supernatant was further centrifuged at 17,000 $\mathrm{g}$ for 15 minutes. Pellets were resuspended in Tris buffer $(100 \mathrm{mM}$ Tris, $1 \mathrm{mM}$ $\mathrm{MgCl}_{2}, 5 \mathrm{mM}$ EGTA, pH 7.4). Membrane samples were frozen by liquid nitrogen and kept under $-70^{\circ} \mathrm{C}$ until assay. Membrane protein was determined by a modified Lowry method ${ }^{17)}$ and adjusted to $0.3 \mathrm{mg} / \mathrm{m} l$ when $\beta$-adrenergic receptor was assayed.

$\boldsymbol{\beta}$-Adrenergic receptor assay: Density of myocardial $\beta$-adrenergic receptors 
was determined by saturation isotherm in triplicate as described previously. ${ }^{15,16)}$ Briefly, 30-800 pM of ${ }^{125}$ I-iodocyanopindolol (Amersham Japan, Tokyo) with $1.7 \times 10^{-6} \mathrm{M}$ propranolol or Tris buffer was added to $100 \mu$ of membrane sample and the mixture incubated at $37^{\circ} \mathrm{C}$ for 60 minutes. Reaction was terminated by adding $750 \mu l$ of ice-cold Tris buffer. The preparations were filtrated through Whatman GF/C filters using a filtration apparatus (Millipore Corp., Bedford, MA, USA) and washed twice with ice-cold Tris buffer. Radioactivity was counted using an ARC-600 gamma counter (Aloka Corp., Tokyo) with a 76.5\% counting efficiency. Specific activity was determined by subtracting nonspecific binding in the presence of propranolol from the total binding. Maximal binding sites and dissociation constant were determined using Scatchard analysis. ${ }^{18)}$

Blood sampling for plasma norepinephrine: A polyethylene catheter was placed in the right jugular vein before production of aortic regurgitation in 5 rabbits each with $\mathrm{AR}+\mathrm{C}$ and $\mathrm{AR}+\mathrm{Dig}$ for determination of plasma norepinephrine concentration. Five $\mathrm{m} l$ of blood were drawn in unanesthetized condition on the following day and 1 week after production of aortic regurgitation.

Data analysis: Hemodynamic data were recorded using a thermal array recorder (Nihon-Kohden, Tokyo) at $200 \mathrm{~mm}$ paper speed. Total forward stroke volume (TSV) and regurgitant volume (RV) were determined by digitization of aortic flow using MYPAD-A3 Logitec DIGITIZER (MODEL K-510, Tokyo). Stroke volume was defined by subtracting the regurgitant volume from the total forward stroke volume, and regurgitant fraction by dividing regurgitant volume by total forward stroke volume. Least squares method was used for Scatchard analysis. Data are expressed as a mean $\pm \mathrm{SD}$. Differences between the three groups were determined by analysis of variance followed by Student t-test. Changes in each group were assessed by paired t-test. Statistical significance was considered to be $p<0.05$.

\section{Results}

No deaths were observed during the observation period. Plasma digoxin concentration was $1.6 \pm 1.1 \mathrm{ng} / \mathrm{m} l$ in $\mathrm{AR}+\mathrm{Dig}$. The Table shows the hemodynamic variables for the three groups. The decrease in aortic diastolic pressure immediately after production of aortic regurgitation was similar between $A R+C$ and AR + Dig. Aortic diastolic pressure and mean pressure were lower in both $\mathrm{AR}+\mathrm{C}$ and $\mathrm{AR}+\mathrm{Dig}$ than sham-operated rabbits, although there was no difference between the two groups for aortic regurgitation. Regurgitant fraction was also similar between the two groups. Left ventricular end-diastolic pressure was higher in $\mathrm{AR}+\mathrm{C}$ than sham-operated rabbits, although it was lower in $\mathrm{AR}+\mathrm{Dig}$ than $A R+C$. Cardiac output was lower in $A R+C$ than sham-operated rabbits. 
Table. Hemodynamic Variables

\begin{tabular}{lccc}
\hline & Sham & AR $+\mathrm{C}$ & AR + Dig \\
\hline dAODP $(\mathrm{mmHg})$ & $/$ & $27 \pm 11$ & $23 \pm 10$ \\
Heart rate $(\mathrm{bpm})$ & $205 \pm 18$ & $224 \pm 21^{*}$ & $217 \pm 24$ \\
LV end-diastolic pressure $(\mathrm{mmHg})$ & $5.7 \pm 2.0$ & $18.0 \pm 6.5^{*}$ & $11.9 \pm 4.6^{*}+$ \\
AoP (mmHg) & & & \\
$\quad$ systolic & $101+22$ & $89 \pm 10$ & $84 \pm 8^{*}$ \\
$\quad$ diastolic & $76 \pm 21$ & $52 \pm 13^{*}$ & $59 \pm 4^{*}$ \\
$\quad$ mean & $84 \pm 21$ & $67 \pm 13^{*}$ & $67 \pm 5^{*}$ \\
Cardiac output $(\mathrm{m} l / \mathrm{min} / \mathrm{kg})$ & $164 \pm 29$ & $128 \pm 33^{*}$ & $145 \pm 30$ \\
Regurgitant fraction $(\%)$ & $/$ & $48 \pm 10$ & $48 \pm 16$ \\
LV diameter $(\mathrm{mm})$ & & & \\
$\quad$ end-diastole & $22.4 \pm 1.3$ & $24.5 \pm 2.6^{*}$ & $22.7 \pm 2.2$ \\
$\quad$ end-systole & $20.7 \pm 1.0$ & $22.7 \pm 2.3^{*}$ & $20.9 \pm 1.9$ \\
\hline
\end{tabular}

$\mathrm{dAODP}=$ decrease in aortic diastolic pressure immediately after production of aortic regurgitation (AR); $\mathrm{LV}=$ left ventricle; $\mathrm{AOP}=$ aortic pressure; $\mathrm{AR}+\mathrm{C}=$ rabbits with $\mathrm{AR}$ given saline; $\mathrm{AR}+\mathrm{Dig}=$ rabbits with $\mathrm{AR}$ given digoxin. ${ }^{*} p<0.05$ compared with sham $+p<0.05$ compared with $\mathrm{AR}+\mathrm{C}$.
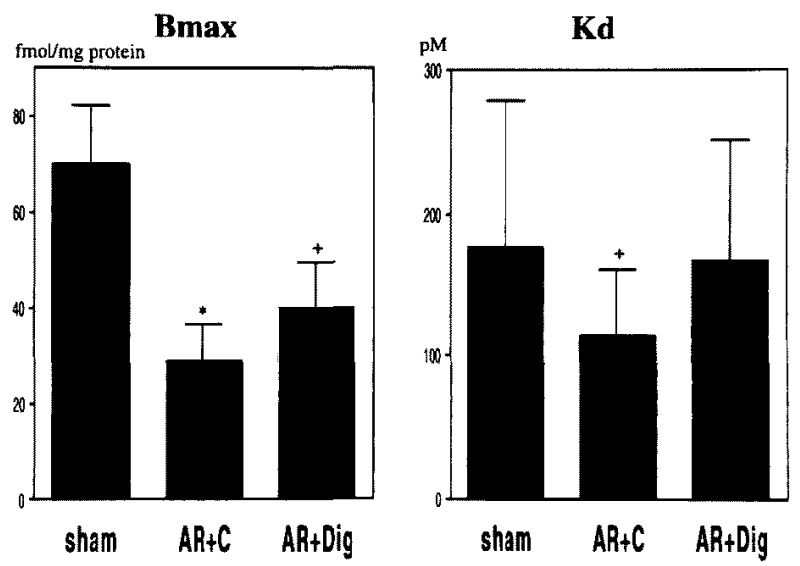

Figure 1. Myocardial $\boldsymbol{\beta}$-adrenergic receptors.

$B \max =$ maximal binding sites; $K d=$ dissociation constant; $A R+C=$ rabbits with aortic regurgitation $(A R)$ given saline; $A R+D i g=$ rabbits with $A R$ given digoxin. $* p<0.05$ compared with sharn; $+p<0.05$ compared with $\mathrm{AR}+\mathrm{C}$.

Both end-diastolic and end-systolic dimensions were larger in $\mathrm{AR}+\mathrm{C}$ than sham-operated rabbits. There was no difference in cardiac output or the dimensions between AR + Dig and sham-operated rabbits.

The left ventricular free wall weight was higher in AR $+\mathrm{C}(0.95 \pm 0.11 \mathrm{~g} /$ $\mathrm{kg})$ than sham-operated rabbits $(0.83 \pm 0.05 \mathrm{~g} / \mathrm{kg}, p<0.05)$. There was no difference between $\mathrm{AR}+\operatorname{Dig}(0.94 \pm 0.12 \mathrm{~g} / \mathrm{kg})$ and sham-operated rabbits. The left ventricular free wall thickness was similar in the three groups (sham-operated rabbits, $3.7 \pm 0.5 \mathrm{~mm}$; AR + C, $3.8 \pm 0.2 \mathrm{~mm}$; AR + Dig, $3.9 \pm 0.1 \mathrm{~mm}$ ). Figure 1 shows maximal binding sites and the dissociation constant of myocardial $\beta$ - 


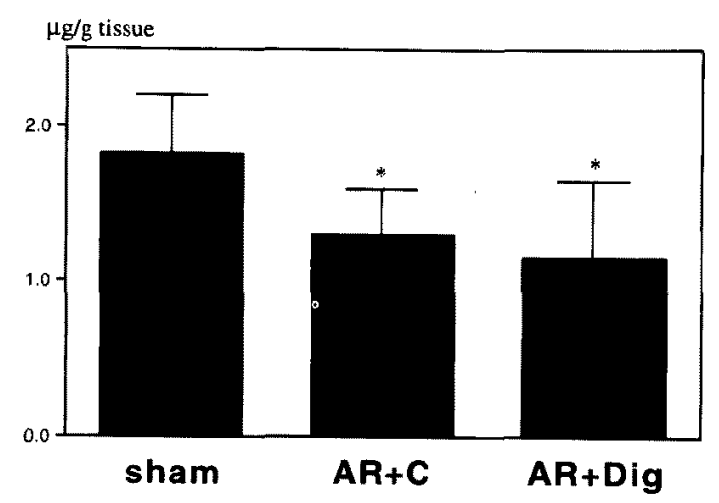

Figure 2. Myocardial norepinephrine content. Abbreviations are described in Figure 1.

adrenergic receptor of the left ventricular free wall. Maximal binding sites were lower in $\mathrm{AR}+\mathrm{C}(28.8 \pm 7.9 \mathrm{fmol} / \mathrm{mg}$ protein) than sham-operated rabbits $(69.9 \pm 12.3 \mathrm{fmol} / \mathrm{mg}$ protein, $p<0.05)$. The number was higher in AR+Dig (39.9 $\pm 9.8 \mathrm{fmol} / \mathrm{mg}$ protein) than $\mathrm{AR}+\mathrm{C}(p<0.05)$. There was no difference in dissociation constant except it was higher in AR + Dig $(167 \pm 83 \mathrm{pM})$ than $\mathrm{AR}+\mathrm{C}(114 \pm 47 \mathrm{pM}, p<0.05)$. Figure 2 presents the myocardial norepinephrine content of the left ventricular free wall. Norepinephrine content was lower in both $\mathrm{AR}+\mathrm{C}(1.30 \pm 0.30 \mu \mathrm{g} / \mathrm{g}$ tissue $)$ and $\mathrm{AR}+\mathrm{Dig}(1.16 \pm 0.49 \mu \mathrm{g} / \mathrm{g}$ tissue $)$ than sham-operated rabbits $(1.83 \pm 0.38 \mu \mathrm{g} / \mathrm{g}$ tissue, $p<0.05$ respectively). There was no difference between $A R+C$ and $A R+D i g$.

Plasma norepinephrine concentration increased from $305 \pm 133 \mathrm{pg} / \mathrm{m} l$ to $589 \pm 132 \mathrm{pg} / \mathrm{m} l$ in $\mathrm{AR}+\mathrm{C}(p<0.05)$, but not in AR + Dig (from $339 \pm 60 \mathrm{pg} /$ $\mathrm{m} l$ to $396 \pm 134 \mathrm{pg} / \mathrm{m} l$ ). Plasma norepinephrine level 1 week after production of aortic regurgitation was lower in $\mathrm{AR}+\mathrm{Dig}$ than $\mathrm{AR}+\mathrm{C}(p<0.05)$.

\section{Discussion}

Aortic regurgitation as an animal model for heart failure: Hemodynamic findings showed that 1 week after induction of aortic regurgitation, left ventricular end-diastolic pressure was elevated and cardiac output reduced despite ventricular enlargement present, suggesting that left ventricular contractile performance was impaired. Down-regulation of myocardial $\beta$-adrenergic receptors and depletion of catecholamines were also observed. In a previous study we found that left ventricular end-diastolic pressure was elevated and $\beta$-adrenergic receptor number reduced as early as 1 day after induction of aortic regurgitation. ${ }^{15)}$ However, neither cardiac output nor myocardial catecholamine level was reduced at that time. Left ventricular function and sympatho-neuronal regulation progres- 
sively deteriorated during the week following induction of aortic regurgitation. Myocardial $\beta$-adrenergic receptor density and norepinephrine content were both reduced in the failing left ventricle although not in the non-failing right ventricle, findings in accordance with the hemodynamic data showing left ventricular failure. ${ }^{19)}$ Gilson et al ${ }^{20)}$ reported that the myocardial $\beta$-adrenergic receptor number was reduced in rabbits with pressure and volume overload. In contrast, Yamazaki et al. ${ }^{21)}$ reported that the number of myocardial $\beta$-adrenergic receptors was increased in rats with aortic regurgitation. Florenzano et al. ${ }^{22}$ reported that left ventricular contractility was increased following induction of aortic regurgitation in chronically instrumented conscious dogs. However, aortic regurgitation induced in our study was severe enough to explain this discrepancy in the findings. Aortic regurgitation can result if severe enough in left ventricular failure in animal models. Magid et al. ${ }^{23}$ produced aortic regurgitation in rabbits, and observed pathological evidence for heart failure. Mean regurgitant fraction was $52 \%$, which is comparable to our study.

Effect of digitalis glycosides on acute left ventricular failure: The left ventricular end-diastolic pressure was higher and cardiac output lower in rabbits with aortic regurgitation than sham-operated rabbits. Left ventricular end-diastolic pressure was lower in rabbits with aortic regurgitation given digoxin than those given saline. There was no difference in cardiac output between rabbits with aortic regurgitation given digoxin and sham-operated rabbits. Likewise, myocardial $\beta$-adrenergic receptor density was lower in rabbits with aortic regurgitation, while the density was higher in rabbits with aortic regurgitation given digoxin than those given saline. Two explanations are possible for the mechanisms of the attenuation of myocardial $\beta$-adrenergic receptor down-regulation. It is conceivable that digitalis glycoside improved hemodynamic status through its positive inotropic action, which in turn resulted in the attenuation of myocardial $\beta$-adrenergic receptor down-regulation.

Alternatively, a growing body of evidence suggests that there are some interactions between digitalis glycosides and sympathetic nervous system activity. First, clinical trials on digoxin show that digitalis glycosides lower plasma norepinephrine levels in patients with heart failure. ${ }^{24-26)}$ In these studies, however, an indirect effect of digoxin through stabilization of hemodynamic variables may explain the decrease in plasma norepinephrine level. Ferguson et al..$^{8)}$ examined the effects of short-term digitalis administration on sympathetic nervous activity in patients with moderate-to-severe heart failure using direct microneurographic recordings of efferent sympathetic nerve activity, and demonstrated that muscle sympathetic nerve activities were attenuated by digitalis glycosides before any detectable improvement in hemodynamic parameters. By contrast, they found that dobutamine which similarly improved hemodynamic parameters did not 
attenuate muscle sympathetic nerve activities. In addition, microneurographic recordings showed that digitalis but not dobutamine or placebo selectively potentiated sympathetic neural responses to baroreflex perturbation induced by lower body negative pressure in normal humans. ${ }^{27)}$ Digitalis glycoside did not alter sympathetic nerve responses to the cold pressure test, suggesting that cardiopulmonary baroreflex function was selectively potentiated by the agent. Leenen et al. ${ }^{28)}$ found that brain ouabain-like activity existed especially in the hypothalamus, using two animal models of heart failure, and reported that intracerebroventricular administration of Fab fragments significantly decreased renal sympathetic nerve activity and plasma norepinephrine level.

Conversely, there are several lines of evidence suggesting that overactivity of the sympathetic nervous system can lead to a decrease in $\mathrm{Na}^{+}, \mathrm{K}^{+}$pump activity, which reflects digitalis-binding site. Fan et al. ${ }^{10)}$ reported that $\mathrm{Na}^{+}, \mathrm{K}^{+}-$ ATPase activity and ${ }^{3} \mathrm{H}$-ouabain binding sites were decreased in myocardium with right ventricular failure induced by progressive pulmonary constriction and tricuspid avulsion, and these alterations were reversed by the $\beta$-blocker nadolol. The same group further showed that $\mathrm{Na}^{+}, \mathrm{K}^{+}$-ATPase $\alpha 3$ isoform protein along with ouabain-binding sites was reduced in failing myocardium induced by rapid ventricular pacing. ${ }^{11}$ Similar findings were noted in intact myocardium administered norepinephrine. They concluded that the decrease in $\mathrm{Na}^{+}, \mathrm{K}^{+}$-ATPase activity seen in congestive heart failure was mediated by excessive activation of the sympathetic nervous system. This finding is consistent with the report by Wang et al. ${ }^{9}$ who showed that perfusion of the carotid sinus with ouabain caused a significant decrease in threshold pressure and a significant increase in peak discharge frequency, as well as an increase in the slope of the carotid sinus pressure-discharge curve in dogs with pacing-induced heart failure. They speculated that carotid sinus $\mathrm{Na}^{+}, \mathrm{K}^{+}$-ATPase activity was stimulated by prolonged activation of the sympathetic nervous system in congestive heart failure, ${ }^{29)}$ resulting in a subsensitivity of carotid sinus baroreceptor function, which was restored by the sodium-potassium pump inhibitors, digitalis glycosides.

In this study, it is possible that digitalis glycosides attenuated excessive activation of the sympathetic nervous system after production of aortic regurgitation resulting in a partial prevention of down-regulation in myocardial $\beta$-adrenergic receptors, although myocardial norepinephrine content in rabbits with aortic regurgitation given saline and those given digoxin was similar. Plasma norepinephrine level was also lower in rabbits given digoxin than those given saline one week after production of aortic regurgitation. Differences in the time course of the regulation may be responsible for the persistent decrease in myocardial norepinephrine content in the presence of the improved $\beta$-adrenergic receptor and plasma norepinephrine. We cannot explain the exact mechanisms of the 
antiadrenergic effects of digoxin in the present study. A recent study has shown that acute administration of digoxin reduces the $\beta$-adrenergic contractile response in intact rabbit hearts. ${ }^{30)}$ The authors speculated that $\mathrm{Ca}^{2+}$ mobilized via $\mathrm{Na}^{+} / \mathrm{Ca}^{2+}$ exchange inhibited the catalytic unit of the adenylate cyclase system without affecting the $\beta$-adrenergic receptor-G protein system or contractile proteins.

Limitations of this study: We examined different groups of rabbits to compare the results, which potentially leads to misinterpretation of the results. The degree of aortic regurgitation was checked immediately after the procedure and again just before obtaining a membrane preparation 1 week after the procedure. Parameters reflecting the volume overloading were essentially the same between the two groups with aortic regurgitation including the decrease in aortic diastolic pressure immediately after production of aortic regurgitation, aortic diastolic pressure and regurgitant fraction 1 week after the procedure. Therefore, we believe the difference between the two groups with aortic regurgitation was not caused by a difference in severity, but rather by a difference in the treatments themselves. Digoxin is not a common therapeutic option for chronic compensated aortic regurgitation. We showed that digoxin was effective in restoring the hemodynamics and $\beta$-adrenergic receptor regulation in acute left ventricular failure induced by aortic regurgitation.

\section{REFERENCES}

1. Milrinone Multicenter Trial Group. A comparison of oral milrinone, digoxin, and their combination in the treatment of patients with chronic heart failure. N Engl J Med 1989; 320: 677-683.

2. The Xamoterol in Severe Heart Failure Study Group. Xamoterol in severe heart failure. Lancet 1990; 336: $1-6$.

3. The PROMISE Study Research Group. Effect of oral milrinone on mortality in severe chronic heart failure. N Engl J Med 1991; 325: 1468-75.

4. Feldman MD, Copelas L, Gwathmey JK, et al. Deficient production of cyclic AMP: pharmacologic evidence of an important cause of contractile dysfunction in patients with end-stage heart failure. Circulation 1987; 75: 331-9.

5. The Captopril-Digoxin Multicenter Research Group. Comparative effects of therapy with captopril and digoxin in patients with mild to moderate heart failure. JAMA 1988; 259: 539-44.

6. RADIANCE Study Group. Withdrawal of digoxin from patients with chronic heart failure treated with angiotensin-converting-enzyme inhibitors. N Engl J Med 1993; 329: 1-7.

7. Bristow MR, Ginsburg R, Minobe W, et al. Decreased catecholamine sensitivity and beta-adrenergicreceptor density in failing human hearts. N Engl J Med 1982; 307: 205-11.

8. Ferguson DW, Berg WJ, Sanders JS, Roach PJ, Kempf JS, Kienzle MG. Sympathoinhibitory responses to digitalis glycosides in heart failure patients: direct evidence from sympathetic neural recordings. Circulation 1989; 80:65 77.

9. Wang W, Chen J-S, Zucker IH. Carotid sinus baroreceptor sensitivity in experimental heart failure. Circulation 1990; 81: 1959-66.

10. Fan TM, Frantz RP, Elam H, Sakamoto S, Imai N, Liang C-S. Reductions of myocardial Na-K$\Lambda \mathrm{TPase}$ activity and ouabain binding sites in heart failure: prevention by nadolol. Am J Physiol 1993; 265: H2086-93. 
11. Kim CH, Fan TM, Kelly PF, et al. Isoform-specific regulation of myocardial Na,K-ATPase $\alpha$-subunit in congestive heart failure: role of norepinephrine. Circulation 1994; 89: 313-20.

12. Wainai $Y$, Kusuhara $M$, Yamada $T$, et al. Atrial natriuretic peptide secretion in rabbits with aortic regurgitation. Res Exp Med 1990; 190: 13-8.

13. Wainai $\mathrm{Y}$. Adaptive mechanisms of the aorta and left ventricle to volume overloading following aortic regurgitation in rabbits. Cardiovasc Res 1991; 25: 463-7.

14. Taylor RB, Reid R, Kendle KE, Geddes G, Curle PF. Assay procedures for the determination of biogenic amines and their metabolites in rat hypothalamus using ion-pairing reversed-phase high-performance liquid chromatography. J Chromatogr 1983; 277; 101-14.

15. Yoshikawa T, Handa S, Yamada T, et al. Sequential changes in sympatho-neuronal regulation and contractile function following aortic regurgitation in rabbit heart. Eur Heart J 1993; 14: 1404-9.

16. Yoshikawa T, Handa S, Nagami K, et al. Effect of the angiotensin-converting enzyme inhibitor alacepril on ventricular function and beta-adrenoceptor number in rabbits with aortic regurgitation. Jpn Heart J 1995; 36: 91-100.

17. Peterson GL. A simplification of the protein assay method of Lowry et al. which is more applicable. Anal Biochem 1977; 83: 346-56.

18. Scatchard G. The attractions of proteins for small molecules and ions. Ann NY Aca Sci 1949; 51: 660-72.

19. Yoshikawa T, Handa S, Suzuki M, Nagami K. Abnormalities in sympathoneuronal regulation are localized to failing myocardium in rabbit heart. J Am Coll Cardiol 1994; 24: 210-5.

20. Gilson N, Bouanani NEH, Corsin A, Crozatier B. Left ventricular function and $\beta$-adrenoceptors in rabbit failing heart. Am J Physiol 1990; 258: H634-41.

21. Yamazaki T, Uematsu T, Mizuno A, Takiguchi Y, Nakashima M. Alterations of cardiac adrenoceptors and calcium channels subsequent to production of aortic insufficiency in rats. Arch Int Pharmacodyn 1989; 299: 155-68.

22. Florenzano $\mathrm{F}$ and Glantz $\mathrm{SA}$. Left ventricular mechanical adaptation in chronic aortic regurgitation in intact dogs. Am J Physiol 1987; 252: H969-79.

23. Magid NM, Opio G, Wallerson DC, Young MS, Borer JS. Heart fallure due to chronic experimental aortic regurgitation. Am J Physiol 1994; 267: H556-62.

24. Ribner HS, Plucinski DA, Hsieh A-M, et al. Acute effects of digoxin on total systemic vascular resistance in congestive heart failure due to idiopathic dilated cardiomyopathy: a hemodynamic-hormonal study. Am J Cardiol 1985; 56: 896-904.

25. Gheorghiade M, Hall V, Lakier JB, Goldstein S. Comparative hemodynamic and neurohumoral effects of intravenous captopril and digoxin and their combinations in patients with severe heart failure. J Am Coll Cardiol 1989; 13: 134-42.

26. DIMT Study Group. Double-blind placebo-controlled study of ibopamine and digoxin in patients with mild to moderate heart fallure. J Am Coll Cardiol 1993; 22: 1564-73.

27. Schobel HP, Oren RM, Roach PJ, Mark AL, Ferguson DW. Contrasting effects of digitalis and dobutamine on baroreflex sympathetic control in normal humans. Circulation 1991; 84: 1118-29.

28. Leenen FHH, Huang BS, Yu H, Yuan B. Brain 'ouabain' mediates sympathetic hyperactivity in congestive heart failure. Circ Res 1995; 77: 993-1000.

29. Hougen TJ, Spicer N, Smith TW. Stimulation of monovalent cation active transport by low concentrations of cardiac glycosides: role of catecholamines. J Clin Invest $1981 ; 68: 1207-14$.

30. Nagai $K$, Murakami T, Iwase T, Tomita T, Sasayama S. Digoxin reduces $\beta$-adrenergic contractile response in rabbit hearts: $\mathrm{Ca}^{2+}$-dependent inhibition of adenylyl cyclase activity via $\mathrm{Na}^{+} / \mathrm{Ca}^{2+}$ exchange. J Clin Invest 1996; 97:6-13. 